Revista Cadernos de Economia

Universidade Comunitária da Região de Chapecó - Unochapecó

\title{
Administração Pública Municipal no Oeste Catarinense: uma Análise de INDICADORES POLÍTICO-INSTITUCIONAIS
}

\section{Municipal Administration in the Western Region of SANTa Catarina (Brazil): AN ANALYSIS OF POLITICAL-INSTITUTIONAL INDICATORS}

Leonardo Secchi ${ }^{1}$ https://orcid.org/0000-0002-9073-0343

Luciane Beiro de Souza Machado ${ }^{2}$ https://orcid.org/0000-0003-3941-926

Submissão: 15/07/2020 / Aceito: 27/10/2020.

\begin{abstract}
Resumo
O presente artigo tem como objetivo apresentar um panorama das administrações públicas municipais nos municípios do Oeste de Santa Catarina quanto às finanças públicas, qualidade da gestão pública e participação cidadã. Como fonte de dados adotou-se o Sistema de Indicadores de Desenvolvimento Municipal Sustentável (SIDEMS) elaborado pela Federação Catarinense de Municípios (FECAM). Ao todo foram analisadas 10 indicadores e 16 variáveis de 118 municípios do Oeste catarinense, com dados referentes à dimensão políticoinstitucional do SIDEMS no ano de 2018. As análises comparativas foram realizadas entre os municípios do Oeste, destacando os índices mais altos e mais baixos, os 10 maiores municípios do Oeste e comparando as médias regionais com a média geral dos municípios de Santa Catarina. Os resultados apontam para uma situação comparativamente favorável dos municípios do Oeste catarinense nos indicadores das três subdimensões de finanças públicas, gestão pública e participação social. Os indicadores dos municípios do Oeste apenas são inferiores à média municipal de Santa Catarina apenas no que se refere a elaboração de planos de desenvolvimento setoriais (média 0,730, contra 0,757 do restante de Santa Catarina), , cadastro de ISS informatizado (de 0,958, contra 0,969 de toda Santa Catarina) e percentual de receita própria sobre a receita corrente líquida, dependendo em $92,76 \%$ de recursos provenientes de transferências federais e estaduais, contra uma média geral de 90,22\% dos municípios de Santa Catarina. Como conclusão pode-se afirmar que Administrações Públicas municipais do Oeste catarinense apresentam, em média, indicadores político-institucionais superiores à média dos municípios de Santa Catarina (índice médio de 0,674), mas existe um espaço para melhoria na área de arrecadação tributária própria, informatização do cadastro de ISS e no desenvolvimento de planos de desenvolvimento setoriais nas áreas de saneamento básico, gestão de resíduos, educação, saúde, segurança pública e plano diretor.
\end{abstract}

Palavras-chave: Administração Pública; Administração Municipal; Indicadores de Desenvolvimento; Oeste de Santa Catarina.

\footnotetext{
${ }^{1}$ Professor do Programa de Pós-Graduação em Administração da Universidade do Estado de Santa Catarina (PPGA/ESAG/UDESC). Doutor em Estudos Políticos pela Universidade de Milão (Itália). E-mail: leonardo.secchi@udesc.br.

${ }^{2}$ Auditora de Controle Externo do Tribunal de Contas do Estado de Santa Catarina (TCE-SC). Mestranda em Administração no Programa de Pós-Graduação Profissional em Administração da Universidade do Estado de Santa Catarina (PPGA/ESAG/UDESC). E-mail. lucianebsm@gmail.com .
} 


\title{
Revista Cadernos de Economia
}

Universidade Comunitária da Região de Chapecó - Unochapecó

\begin{abstract}
This paper has the objective to present an overview of the municipal administration at the Western region of Santa Catarina (Brazil), focused on public finances, quality of public management, and citizen's participation. As source of data we used the Sistema de Indicadores de Desenvolvimento Municipal Sustentável (SIDEMS), a dashboard of indicators of municipal administration maintained by the Federation of Municipalities of Santa Catarina (FECAM). We analyzed the most recent data available (2018) of 10 political-institutional indicators and 16 variables of 118 municipalities in the region. The comparative analysis was pursued by highlighting the top and lower scores, the top 10 largest municipalities and by comparing the regional means with the means of the overall indexes for Santa Catarina. The results point to an overall positive outcome in indicators of public finances, quality of public management, and citizen's participation. The only indicators that the municipalities in the regional performed below the State average ware the locally-collected revenues as a percentage of total revenues, the elaboration of policy areas plans and the digitalization of the register of municipal service's tax revenues. As a conclusion, we can point that Public Administration in municipalities in the Western region of Santa Catarina (Brazil) present, on average, better political-institutional performance indicators than the state's average. Although, there is room for improvement in the areas of fiscal effort to collect their own tax revenues, the informatization of municipal service's tax revenues and the formulation of policy plans in areas such as sanitation, solid waste management, health, education, safety and urban master plans.
\end{abstract}

Keywords: Public Administration; Municipal Management; Performance Indicators; Brazil.

\section{INTRODUÇÃO}

A gestão da administração pública é uma tarefa difícil, especialmente no Brasil (Castor, 2004). Os agentes políticos (cargos eletivos e comissionados) que assumem o executivo municipal são desafiados a gerir uma máquina pública altamente diversificada funcionalmente, sob um marco regulatório pesado e com escassez de recursos.

A partir da Constituição de 1988 os municípios passaram a assumir uma gama variada de responsabilidades, que vão desde a saúde (ex. postos de saúde, campanhas preventivas, distribuição de remédios, etc), educação (ex. creches, escolas municipais, bibliotecas), cultura e desporto (ex. realização de eventos culturais, cursos de artes, museus, treinamento de equipes esportivas, etc), serviço social (ex. implementação de políticas nacionais, habitação, conselhos tutelares, assistência, etc), obras (ex. pavimentação, saneamento, coleta de lixo, manutenção de pontes, vias públicas, estradas, cemitérios, etc), além de desenhar e implementar políticas para o desenvolvimento econômico nas áreas de agricultura, turismo, meio ambiente, indústria, comércio, dentre outras. 


\section{Revista Cadernos de Economia}

Universidade Comunitária da Região de Chapecó - Unochapecó

Além da variedade funcional, as prefeituras municipais sofrem com pesada carga regulatória imposta pelos níveis superiores da federação. A discricionariedade do gestor público municipal é regulamentada por leis de licitações e contratos (Lei 8.666/93), leis de responsabilidade fiscal (Lei 101/2000), leis relativas à política fiscal e à gestão de pessoas contidas na Constituição de 1988 e emendas subsequentes, e tantas outras leis nas áreas finalísticas de saúde, educação, segurança, saneamento, etc. Apesar da euforia descentralizadora pós-1988, ainda existe no Brasil um sistema federativo fortemente centralizado, tanto do ponto de vista regulatório quanto tributário (ARRETCHE, 2012).

Na questão tributária, é recorrente a reclamação do movimento municipalista quanto à repactuação federativa na distribuição das receitas tributárias (CNM, 2008). Enquanto a União retém aproximadamente $55 \%$ de todas as receitas tributárias (receitas + fundos de desenvolvimento regional), estados ficam com $21,5 \%$ e todos os 5.570 municípios do Brasil ficam com 23,5\% (SENADO, 2014). Além da escassez de recursos financeiros para fazer frente à quantidade e variedade de serviços municipais, as Prefeituras enfrentam o desafio de atração e retenção de recursos humanos qualificados. Os limites impostos pela legislação e a diferença salarial dos cargos municipais comparados aos cargos em nível estadual e federal dificultam a contratação e retenção de médicos, enfermeiros, pessoal de TI, entre outros.

Para enfrentar estas dificuldades, em Santa Catarina, gestores públicos municipais têm encontrado soluções inovadoras pela via do associativismo municipal (MARQUES, DIAS, 2003; SIEBERT, 2010; ABRUCIO, FILIPPIM, DIEGUEZ, 2013). Desde a década de 1960 os municípios catarinenses passaram a associar-se regionalmente com vistas à troca de experiências, realização de parcerias intermunicipais na oferta de serviços (ex. coleta de lixo, compartilhamento de maquinário, transporte metropolitano, etc.), e em processos licitatórios para gerar economia de escala. Existem atualmente 21 associações de municípios em todas as regiões de Santa Catarina, reunidas sob a Federação Catarinense de Municípios (FECAM, 2020).

A FECAM tem função expressa de defesa de interesses dos municípios frente aos órgãos governamentais e prestado assessoria técnica nas áreas jurídica, contábil, informática e capacitação de pessoal. Esta organização representa um movimento associativo municipal estadual, que são operacionalizadas com a realização de eventos, cursos de capacitação aos 


\section{Revista Cadernos de Economia}

Universidade Comunitária da Região de Chapecó - Unochapecó

servidores, estímulo à cooperação e consórcios intermunicipais, além da criação do Sistema de Indicadores de Desenvolvimento Municipal Sustentável (SIDEMS).

O SIDEMS serviu de fonte de dados para esta pesquisa que teve como objetivo central apresentar panorama das administrações públicas municipais nos municípios do Oeste de Santa Catarina, quanto às finanças públicas, qualidade da gestão pública e participação cidadã. O recorte do estudo recaiu sobre 118 municípios do Oeste catarinense, com dados referentes à dimensão político-institucional do SIDEMS no ano de 2018, o mais recente disponível. As análises comparativas foram realizadas entre os municípios do Oeste, destacando os índices mais altos e mais baixos, os 10 maiores municípios do Oeste e comparando as médias regionais com a média geral dos municípios do estado.

\section{METODOLOGIA ADOTADA PARA VERIFICAÇÃO DO DESENVOLVIMENTO POLÍTICO-INSTITUCIONAL MUNICIPAL}

Como apontam Abrucio, Filippim e Dieguez (2013), a prática associativista de caráter municipalista presente em Santa Catarina é uma das mais antigas e mais estruturadas da Federação brasileira, sendo que as associações de municípios foram criadas por iniciativa dos prefeitos a partir da década de 1960. Estas associações municipais deram origem à Federação Catarinense de Municípios (FECAM), criada em 1980, tendo como elemento norteador "a filosofia da cooperação para o enfrentamento de problemas nos quais haja interdependência dos municípios [...]” (ABRUCIO, FILIPPIM E DIEGUEZ, 2013, p. 1557).

As associações de municípios atuam na defesa dos interesses municipalistas e na assessoria técnica aos municípios e a FECAM, junta atividade de advocacy federativa com assessoria técnica aos municípios e associações regionais (ABRUCIO, FILIPPIM E DIEGUEZ (2013). Uma das preocupações da FECAM é com o desenvolvimento sustentável dos municípios, o que motivou a elaboração do SIDEMS. Este Sistema tem a finalidade de coletar, tratar e consolidar conteúdos estratégicos para os municípios, facilitando o acesso aos agentes públicos e pesquisadores a dados que originalmente se encontram espalhados e fragmentados em diversas instituições e órgãos governamentais (RÉUS, 2012; SIDEMS, 2018). Este Sistema é composto por quatro dimensões: Sociocultural, Econômica, Ambiental e Político-institucional. 


\section{Revista Cadernos de Economia}

Universidade Comunitária da Região de Chapecó - Unochapecó

Para este artigo foi delimitada a coleta de dados no SIDEMS nos municípios pertencentes às seguintes associações da Mesorregião Oeste Catarinense:

- AMOSC (Associação dos Municípios do Oeste de Santa Catarina);

- AMARP (Associação dos Municípios do Alto Vale do Rio do Peixe);

- AMNROESTE (Associação dos Municípios do Noroeste Catarinense);

- AMERIOS (Associação dos Municípios do Entre Rios);

- AMEOSC (Associação dos Municípios do Extremo Oeste de Santa Catarina);

- AMAI (Associação dos Municípios do Alto Irani);

- AMAUC (Associação dos Municípios do Alto Uruguai Catarinense);

- AMMOC (Associação dos Municípios do Meio Oeste Catarinense).

Cabe registrar que o município de Timbó Grande, que pertence à Associação dos Municípios do Alto Vale do Rio do Peixe (AMARP), não se insere na Mesorregião Oeste Catarinense, mas sim na Região Norte Catarinense, razão pela qual os dados a ele relativos não são considerados no presente estudo.

Para os objetivos deste artigo interessam os dados relativos à dimensão Políticoinstitucional, visto que agrega informações referentes às finanças públicas, gestão pública e participação social nas Administrações Públicas dos municípios do Oeste catarinense. 


\section{Revista Cadernos de Economia}

Universidade Comunitária da Região de Chapecó - Unochapecó

\begin{tabular}{|c|c|c|c|}
\hline & Subdimensão & Indicador & $\begin{array}{r}\text { Variável } \\
\end{array}$ \\
\hline \multirow{16}{*}{$\begin{array}{l}\text { Dimensão } \\
\text { Político- } \\
\text { Institucional }\end{array}$} & \multirow{7}{*}{$\begin{array}{l}\text { Finanças } \\
\text { Públicas }\end{array}$} & \multirow[b]{2}{*}{$\begin{array}{l}\text { Capacidade de } \\
\text { Receita }\end{array}$} & Receita Corrente Líquida Per Capita \\
\hline & & & $\begin{array}{l}\text { Percentual de receita própria sobre a } \\
\text { Receita Corrente Líquida }\end{array}$ \\
\hline & & \multirow[b]{2}{*}{$\begin{array}{l}\text { Estímulo ao } \\
\text { Investimento }\end{array}$} & Investimento público per capita \\
\hline & & & $\begin{array}{l}\text { Percentual de investimento público sobre a } \\
\text { Receita Corrente Líquida }\end{array}$ \\
\hline & & \multirow{3}{*}{ Saúde Financeira } & $\begin{array}{l}\text { Percentual de Endividamento Público } \\
\text { Municipal }\end{array}$ \\
\hline & & & Suficiência de Caixa \\
\hline & & & $\begin{array}{l}\text { Percentual da Receita comprometida com } \\
\text { Folha de Pessoal }\end{array}$ \\
\hline & \multirow{7}{*}{ Gestão Pública } & $\begin{array}{l}\text { Articulação com o } \\
\text { exterior }\end{array}$ & $\begin{array}{l}\text { Participação em Consórcios } \\
\text { Intermunicipais }\end{array}$ \\
\hline & & $\begin{array}{l}\text { Capacidade de } \\
\text { Planejamento } \\
\end{array}$ & Planos de Desenvolvimento Setoriais \\
\hline & & $\begin{array}{l}\text { Qualidade do Quadro } \\
\text { Funcional }\end{array}$ & $\begin{array}{l}\text { Percentual de Servidores com Curso } \\
\text { Superior }\end{array}$ \\
\hline & & \multirow{3}{*}{ Gestão Financeira } & Cadastro Imobiliário Informatizado \\
\hline & & & Cadastro de ISS Informatizado \\
\hline & & & Planta Genérica de Valores Informatizada \\
\hline & & Governo Eletrônico & $\begin{array}{l}\text { Serviços Disponibilizados no Portal do } \\
\text { Município }\end{array}$ \\
\hline & \multirow{2}{*}{$\begin{array}{l}\text { Participação } \\
\text { Social }\end{array}$} & Participação Eleitoral & $\begin{array}{l}\text { Percentual de Participação nos Pleitos } \\
\text { Eleitorais }\end{array}$ \\
\hline & & $\begin{array}{l}\text { Representatividade } \\
\text { de Gêneros }\end{array}$ & $\begin{array}{l}\text { Percentual de Representatividade de } \\
\text { Gêneros entre Candidatos a Vereadores }\end{array}$ \\
\hline
\end{tabular}

Fonte: SIDEMS (2018).

O estabelecimento de indicadores como o SIDEMS é útil para fazer comparações diacrônicas (ao longo do tempo) e sincrônicas (no mesmo tempo, mas em diferentes territórios). Apesar das críticas ao atual formato do SIDEMS, suas dimensões, indicadores e metodologia de atualização dos seus dados (Frare, 2019), sua construção foi legitimada no seio da Federação Catarinense de Municípios e em conjunto com as Associações Municipais.

Neste estudo, adotou-se o Sistema de Indicadores de Desenvolvimento Municipal Sustentável (SIDEMS) elaborado pela Federação Catarinense de Municípios (FECAM) como fonte de dados para o estudo. Ao todo foram analisadas 10 indicadores e 16 variáveis de 118 municípios do Oeste catarinense, com dados referentes à dimensão político-institucional do SIDEMS no ano de 2018. As análises comparativas foram realizadas entre os municípios do 


\section{Revista Cadernos de Economia}

Universidade Comunitária da Região de Chapecó - Unochapecó

Oeste, destacando os índices mais altos e mais baixos, os 10 maiores municípios do Oeste e comparando as médias regionais com as médias geral municípios de Santa Catarina. Limitamos a análise à dimensão político institucional, como metodologia de análise comparada, em suas 16 variáveis presentes no quadro 1. A comparação é realizada sob três perspectivas: 1) identificação dos municípios mais destacados positiva e negativamente nos indicadores, 2) análise dos desempenhos dos 10 maiores municípios do Oeste em cada indicador; e 3) comparação das médias de cada um dos indicadores dos municípios do Oeste com as médias geral municípios catarinenses.

Como limitações do estudo, apresentamos a incapacidade de realizar inferências explicativas sobre o maior ou menor nível de desenvolvimento dos indicadores nos municípios estudados. Os dados disponíveis são descritivos no sentido do detalhamento das subdimensões, variáveis e indicadores. Este estudo limita-se a apresentar, debater e comparar os dados da região com os dados agregados do restante do estado de Santa Catarina.

\section{INDICADORES DE FINANÇAS PÚBLICAS}

As finanças públicas das administrações públicas municipais são relevantes para entender o quanto as Prefeituras conseguem manter recursos financeiros suficientes para fazer frente às obrigações. Desde a carta Constitucional de 1988 os municípios brasileiros têm recebido atribuições na elaboração de políticas públicas e fornecimento de serviços públicos que exigem uma gestão fiscal responsável, tanto do lado da receita quanto do lado das despesas públicas (CLEMENTINO, 2000). As finanças públicas dependem de capacidade de receita do fisco municipal, do estímulo ao investimento e da saúde financeira com relação aos gastos com pessoal e custeio da máquina pública.

\section{Capacidade de receita}

Com relação à capacidade de receita, duas variáveis são analisadas: receita corrente líquida per capita $(\mathrm{R} \$)$ e o percentual de receita própria sobre a receita corrente líquida.

Receita corrente líquida per capita $(\mathrm{R} \$)$ 


\section{Revista Cadernos de Economia}

Universidade Comunitária da Região de Chapecó - Unochapecó

A receita corrente líquida per capita considera o valor da Receita Corrente Líquida declarada pelos municípios em relação a população estimada no exercício. Esta variável ajuda a analisar o quanto cada município consegue arrecadar, normalizando os dados de acordo com o tamanho populacional do município. Os dados referem-se ao ano fiscal de 2016. O município de Lajeado Grande aparece como aquele que possui maior receita corrente líquida per capita, em valores de $\mathrm{R} \$ 9.259,83$, enquanto o município de Guatambu aparece com apenas $\mathrm{R} \$ 1.852,97$, na pior colocação entre os municípios do Oeste catarinense. A média dos municípios do Oeste catarinenses é de $\mathrm{R} \$ 4.498,96$ de receitas per capita, superior à média geral catarinense que é de $\mathrm{R} \$ 3.769,76$ per capita. A capacidade de arrecadação dos municípios está fortemente vinculada à organização e gestão fiscal do município, com capacidade de arrecadação do Imposto sobre Propriedade Territorial Urbana (IPTU), Imposto sobre Serviços de Qualquer Natureza (ISS) e Imposto sobre Transferências de Bens e Imóveis (ITBI), bem como demais taxas, contribuições de melhoria e transferências governamentais provenientes de fundos federais, como o Fundo de Participação dos Municípios (FPM).

Percentual de receita própria sobre a receita corrente líquida (\%)

A independência financeira de um município é medida pelo percentual de receita própria, sobre o total das receitas. Um município que depende de seus próprios esforços fiscais para arrecadação de IPTU, ISS ITBI, taxas de serviços municipais e contribuições de melhoria possui maior autonomia para realização de investimentos não vinculados a determinações dos outros entes federativos (estado e união). Neste quesito, os dados coletados apontam para uma situação de déficit dos municípios do Oeste quando comparados aos demais municípios catarinenses. Enquanto no restante do estado de Santa Catarina a média é de 9,78\% de arrecadação própria, a média dos municípios do Oeste é de apenas 7,24\%. Ou seja, os municípios do Oeste dependem em 92,76\% de recursos provenientes de transferências federais e estaduais. Enquanto são maiores os percentuais de arrecadação própria em municípios-polo como Xaxim (70,12\%), Joaçaba (23,45\%) e Chapecó (22,66\%), em municípios menores existe quase total dependência de verbas intergovernamentais. $O$ município de Matos Costa é o mais dependente, com apenas 1,76\% de arrecadação própria. 


\section{Revista Cadernos de Economia}

Universidade Comunitária da Região de Chapecó - Unochapecó

Para efeitos comparativos, Florianópolis possui uma arrecadação própria de 50,39\% e Balneário Camboriú arrecada 33,83\% com esforços próprios. Esta variável é fortemente dependente do tamanho do município, do perfil econômico e da organização da estrutura administrativa de arrecadação tributária, que em geral reflete nos valores dos imóveis (base geradora para o IPTU e ITBI) e na estrutura de arrecadação de serviços privados (base geradora para o ISS).

\section{Estímulo ao investimento}

Com relação ao investimento, duas variáveis são analisadas: investimento público per capita $(\mathrm{R} \$)$ e o investimento público sobre a receita corrente líquida (em percentual).

Investimento público per capita $(\mathrm{R} \$)$

O investimento público per capita reflete o quanto a Administração Pública municipal consegue destinar verbas para aquisição de equipamentos, máquinas e realização de obras públicas como escolas, creches, estrutura de saneamento, habitação e equipamentos esportivos e turísticos. Os valores são ponderados pelo tamanho da população e os dados são relativos ao ano fiscal de 2016. O município de Jardinópolis aparece como aquele que possui maior capacidade de investimento anual per capita, com valores de $\mathrm{R} \$ 1.677,69$, enquanto o município de Calmon consegue investir apenas $\mathrm{R} \$ 55,47$ por habitante/ano, na pior colocação entre os municípios do Oeste catarinense. A média dos municípios do Oeste catarinenses é de $\mathrm{R} \$ 500,22$ de investimentos per capita, superior à média geral catarinense que é de $\mathrm{R} \$ 415,58$ de investimentos anuais per capita. A capacidade de investimento reflete o quanto os municípios conseguem destinar recursos para novas frentes de iniciativa pública, desvencilhando-se de gastos com folha de pessoal e custeio da máquina pública. É importante ponderar que a capacidade de investimento é cíclica, afinal investimentos realizados no tempo presente passam a demandar recursos com custeio (ex. manutenção, água, energia, gasolina) em exercícios fiscais posteriores. Um município com boa capacidade de investimento é, portanto, aquele que consegue manter um percentual constante de investimentos no médio e 


\section{Revista Cadernos de Economia}

Universidade Comunitária da Região de Chapecó - Unochapecó

longo prazo, ao invés da realização abrupta e pontual de investimentos que depois comprometem a saúde financeira no médio prazo.

Investimento público sobre a Receita Corrente Líquida (\%)

Apontar o percentual de investimento público sobre e receita corrente líquida corresponde a dizer o percentual que o município consegue investir do total arrecadado. Como já ponderado, manter um percentual de investimentos constantes ao longo dos anos é mais saudável que realizar um grande montante de investimentos em um dado ano. Mesmo assim, os municípios que conseguiram extraordinários percentuais de investimentos no ano fiscal de 2018 foram: Dionísio Cerqueira (38,65\%), que já havia conseguido o percentual de 24,97\% em 2012, Erval Velho (33,38\%), mais que quadruplicando os valores atingidos em 2012 $(6,97 \%)$ e São Domingos (32,88\%), que praticamente triplicou os valores de 2012 (11,68\%). O município de Calmon, que também apareceu na última colocação em investimento público per capita, teve o pior percentual com $1,34 \%$ investimento com sobre a receita corrente líquida. A média de investimento sobre receita corrente líquida dos municípios do Oeste foi de $11,11 \%$, ligeiramente superior aos $10,85 \%$ verificados na média estadual. Estes dados refletem que aproximadamente 1/10 (ou 10\%) dos recursos públicos vão para investimentos, enquanto 9/10 (ou 90\%) são destinados ao custeio de máquina pública, pagamento do funcionalismo e amortização de dívidas.

\section{Saúde financeira}

Com relação à saúde financeira, três variáveis são analisadas: endividamento público municipal, receita comprometida com folha de pessoal e suficiência de caixa.

Endividamento público municipal (\%)

O nível de endividamento público municipal é avaliado em função da Dívida Consolidada Líquida (Dívida Consolidada deduzida do saldo relativo aos haveres financeiros - disponibilidade de caixa e demais haveres financeiros) em relação à Receita Corrente Líquida. Nesse aspecto, todos municípios do oeste catarinense têm obtido resultados dentro do benchmark idêntico à média catarinense $(0,988)$.

Percentual da receita comprometida com folha de pessoal (\%) 


\section{Revista Cadernos de Economia}

Universidade Comunitária da Região de Chapecó - Unochapecó

Com a institucionalização da Lei de Responsabilidade Fiscal (Lei Complementar 101/2000), a preocupação com o percentual da receita comprometida com folha de pessoal deixou de ser uma prudência voluntária para ser passível de punição ao gestor público infrator. Segundo a LRF, os municípios podem comprometer no máximo $60 \%$ da Receita Corrente Líquida com gastos de pessoal, sendo $54 \%$ o teto para o poder executivo somado aos $6 \%$ do poder legislativo. O intuito do legislador foi o de incentivar o gestor público a aumentar os investimentos públicos e diminuir despesas correntes com o funcionalismo, em especial os cargos em comissão. Tomando os dados de 2016, a quase totalidade dos municípios do Oeste catarinense cumpre com a LRF. Apenas os municípios de Herval d'Oeste e Bom Jesus ultrapassaram o limite de 60\% com gastos em pessoal, com 60,68\% e $62,96 \%$ respectivamente. Os municípios mais exemplares neste quesito foram Xaxim, Novo Horizonte e Xavantina, que aparecem nas primeiras colocações de todo o estado de Santa Catarina com apenas 18,23\%, 33,76\% e 36,48\% comprometidos com folha de pessoal, respectivamente. A média do comprometimento de receitas com gastos em folha entre os municípios do Oeste catarinense foi de 47,66\%, também melhor que a média dos municípios de toda Santa Catarina, que ficou em 50,28\%.

Suficiência de caixa (\%)

A análise da suficiência de caixa é binária: ou o município possui ou não possui ativos financeiros suficientes para cobrir as obrigações financeiras assumidas. Neste quesito os municípios do Oeste catarinense apresentavam situação favorável, estando com municípios com ativos financeiros suficientes ao fim do ano fiscal de 2016, com exceção do município de Calmon. A média do indicador de suficiência de caixa dos municípios do Oeste catarinense foi 0,99 , em uma escala de 0 a 1 , mesmo patamar da média catarinense. Este indicador apresenta-se como dependente da conjuntura econômica. Dados financeiro-orçamentários de 2014 e 2015 apresentam cenário bem mais desfavorável para a suficiência de caixa dos municípios, vista a queda do ciclo econômico no plano nacional, que afeta diretamente o montante de repasses intergovernamentais às Prefeituras. 


\section{Revista Cadernos de Economia}

Universidade Comunitária da Região de Chapecó - Unochapecó

\section{Síntese dos indicadores de Finanças Públicas}

A agregação dos indicadores referentes a Finanças Públicas mostra um quadro favorável, comparativamente, para os municípios do Oeste Catarinense, mas que ainda há ampla margem de melhoria. Na escala de 0 (baixo índice) até 1 (alto índice) no quesito finanças públicas, o Oeste catarinense ficou com média 0,671, frente à média 0,643 de todo o estado de Santa Catarina. É possível visualizar no quadro 2 os municípios do Oeste com maiores e menores índices em finanças públicas.

Quadro 2 - Melhores e piores índices de Finanças Públicas Municipais - Oeste Catarinense

\begin{tabular}{|l|c|}
\hline \multicolumn{1}{|c|}{ Município } & $\begin{array}{c}\text { Média do Índice de } \\
\text { Finanças Públicas }\end{array}$ \\
\hline 1. Joaçaba & 0,870 \\
\hline 2. Erval Velho & 0,829 \\
\hline 3. Formosa do Sul & 0,822 \\
\hline .. & \\
\hline 116. Romelândia & 0,472 \\
\hline 117. Herval do Oeste & 0,434 \\
\hline 118. Calmon & 0,318 \\
\hline
\end{tabular}

Fonte: SIDEMS (2018).

Joaçaba aparece na primeira colocação (índice $=0,870$ ) entre todos os municípios do Oeste Catarinense quanto às Finanças Públicas. Dos 10 maiores municípios da mesorregião Oeste Catarinense seguem Maravilha (0,756), Videira (0,719), Fraiburgo (0,656), Concórdia $(0,649)$, Xanxerê (0,602), Caçador (0,536), Chapecó $(0,562)$, e São Miguel do Oeste $(0,562)$. Calmon aparece com o pior índice de Finanças Públicas municipais de todos os municípios do Oeste, com índice igual a 0,318. O índice médio de Finanças Públicas municipais dos municípios do Oeste catarinense fica em 0,671, conforme pode ser visualizado na Figura 1. 


\section{Revista Cadernos de Economia}

Universidade Comunitária da Região de Chapecó - Unochapecó

Figura 1 - Mapa do índice de Finanças Públicas - Oeste Catarinense
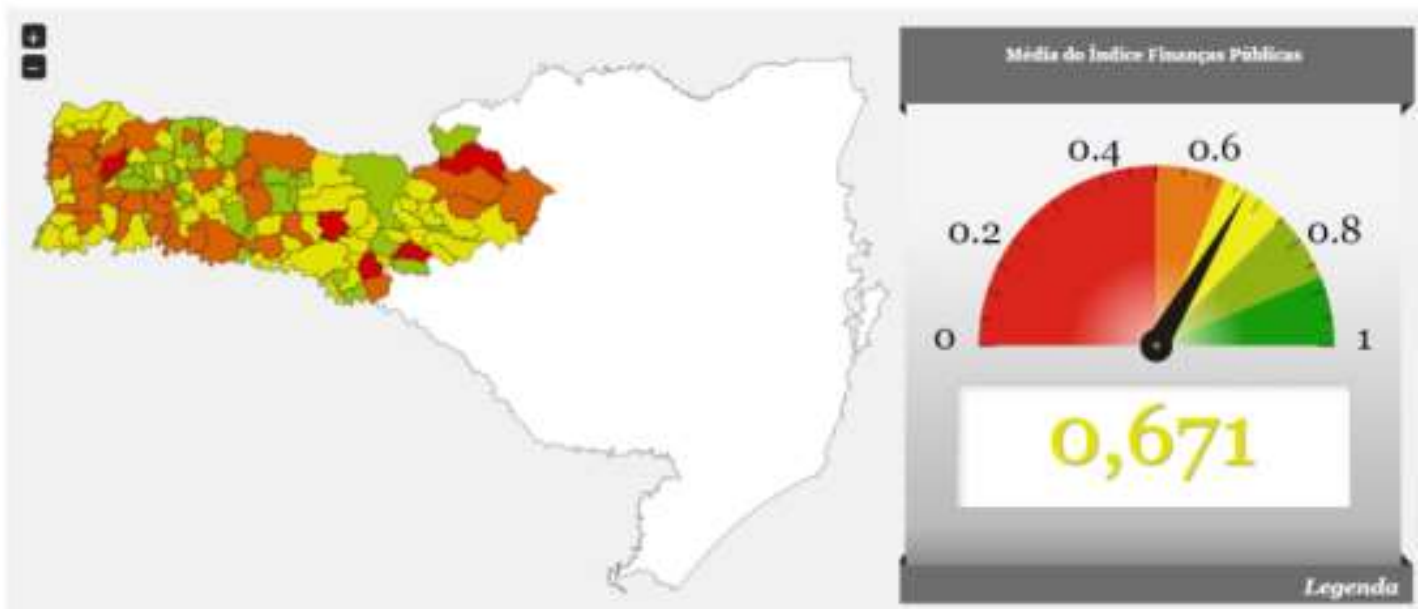

Fonte: SIDEMS (2018).

\section{INDICADORES DE GESTÃO PÚBLICA}

A qualidade da gestão pública é relacionada com a capacidade da Administração em gerenciar seus recursos (humanos, materiais, financeiros etc.) e transformá-los em serviços públicos com valor agregado. Para Santos (2014), as funções administrativas na gestão pública são divididas em planejamento, organização, direção e controle, que tocam transversalmente as grandes áreas de gestão financeira, de pessoas, logística, marketing e gestão de processos e informações no setor público.

No sistema de indicadores da FECAM, nem todas estas áreas estão compreendidas. A qualidade da gestão pública é calculada a partir da verificação de variáveis como a articulação com o exterior (participação em consórcios públicos intermunicipais), capacidade de planejamento (planos de desenvolvimento setoriais), gestão financeira (cadastro imobiliário informatizado, cadastro de ISS informatizado e planta genérica de valores informatizada), governo eletrônico (serviços disponibilizados no portal do município) e qualidade do quadro funcional (percentual de servidores com curso superior).

\section{Articulação com o exterior}




\section{Revista Cadernos de Economia}

Universidade Comunitária da Região de Chapecó - Unochapecó

Com relação à capacidade de articulação da Administração municipal com o exterior é analisada a participação em consórcios intermunicipais (índice) de qualquer área, tais como saúde, educação, habitação, limpeza urbana, coleta e reciclagem de lixo, entre outros.

Participação em consórcios intermunicipais (Índice)

Consórcios intermunicipais são estratégias de articulação entre municípios para criar sinergias no gerenciamento de determinado serviço público. Exemplo disso são os consórcios para gestão de resíduos sólidos em que municípios limítrofes despejam seus rejeitos em um único lugar, diminuindo os custos de gerenciamento e o impacto ambiental. Consórcios existem nas áreas de saúde (ex. aquisição conjunta de remédios), na área de tecnologia da informação (ex. aquisição conjunta de softwares), consórcios para abastecimento de água, ou para aquisição e manutenção de máquinas e equipamentos. Participar em consórcios é uma das formas de melhor gerenciar recursos públicos através de relações intergovernamentais. Esta variável foi binária, sendo $0=$ não participação e 1 =participação em pelo menos um consórcio intermunicipal. Com dados de 2015, com exceção de Coronel Martins, Faxinal dos Guedes e Xavantina, os demais municípios do Oeste catarinense integram pelo menos um consórcio, recebendo, portanto, índice=0,966 nesta variável, contra 0,894 de toda Santa Catarina. Esta é uma realidade em todo o estado de Santa Catarina, em que municípios se organizam, em especial com seus vizinhos para otimizar o gerenciamento de recursos e serviços públicos. Este fenômeno é resultado de uma política deliberada de disseminação dos consórcios municipais pelas Associações dos Munícipios, FECAM e seu colegiado de consórcios públicos.

A FECAM listou 49 Consórcios Intermunicipais presentes em Santa Catarina (FECAM, 2020), sendo que o maior número de Consórcios intermunicipais atende a área de Saúde (19). O Guia aponta também a existência de consórcios multissetoriais e, na maioria, consórcios que atendem áreas específicas: Desenvolvimento regional, Informática, Infraestrutura, Regulação do Serviço de saneamento, Resíduos Sólidos, Saneamento Básico e Meio Ambiente, Sanidade e Segurança Alimentar, Turismo. 


\section{Revista Cadernos de Economia}

Universidade Comunitária da Região de Chapecó - Unochapecó

\section{Capacidade de planejamento}

Com relação à capacidade planejamento apenas uma variável é analisada: a existência de planos de desenvolvimento setoriais.

Existência de planos de desenvolvimento setoriais

Planos de desenvolvimento setoriais são instrumentos de planejamento de médio prazo em gestão pública municipal para delimitar objetivos, estratégias e ações necessárias para o desenvolvimento. São considerados básicos o plano de gestão municipal integrada de resíduos sólidos conforme política nacional de resíduos sócios, o plano municipal de saneamento básico, o plano municipal de educação, o plano municipal de saúde, o plano de segurança pública e o plano diretor (SIDEMS, 2018). Dentre os municípios do Oeste catarinense, dezenove receberam índice máximo com utilização integral de planos de desenvolvimento setoriais: Arroio Trinta, Concórdia, Cordilheira Alta, Coronel Freitas, Iomerê, Ipumirim, Itá, Lacerdópolis, Luzerna, Palmitos, Rio das Antas, Riqueza, Salto Veloso, Santa Helena, São Lourenço do Oeste, Serra Alta, Tigrinhos, Videira e Xanxerê. Os municípios do Oeste que menos utilizam este instrumento de gestão são Águas Frias, Belmonte, Caibi, Campo Erê, Galvão, Lajeado Grande, Maravilha, Palma Sola, Peritiba, Ponte Serrada, Tunápolis e Vargem Bonita, todos com índice 0,287. A média desta variável na região Oeste Catarinense ficou em 0,730, um pouco abaixo do índice médio dos municípios de toda Santa Catarina, que foi de 0,757 .

\section{Gestão Financeira}

A avaliação da gestão financeira contempla a organização dos municípios em relação à existência de cadastro imobiliário e de ISS informatizados, além da planta genérica de valores informatizada, que refletem a capacidade de arrecadar seus tributos. A Região Oeste possui índice 0,951 nesse quesito.

Cadastro imobiliário informatizado (un) 


\section{Revista Cadernos de Economia}

Universidade Comunitária da Região de Chapecó - Unochapecó

Esta variável considera a existência de cadastro imobiliário informatizado no município. Os municípios da região oeste foram muito bem avaliados nesse quesito, com média de 0,987 praticamente empatado com Santa Catarina $(0,988)$, o que demonstra que a grande maioria já possui cadastro imobiliário informatizado. Apenas os municípios de Nova Itaberaba, Peritiba e Santiago do Sul possuem cadastro imobiliário que ainda não foi informatizado.

Cadastro de ISS informatizado (un)

A existência de cadastro de ISS informatizado ou não informatizado, e ainda a inexistência desse cadastro foram avaliadas nessa variável. Novamente os municípios da região oeste tiveram bom desempenho, com 92,37\% dos municípios alcançando índice máximo, perfazendo um índice regional de 0,958, contra 0,969 de toda Santa Catarina. Somente os municípios de Campo Erê, Ibicaré, Palma Sola, Saltinho, São Domingos, Sul Brasil, Tigrinhos e Xavantina ainda não informatizaram o seu cadastro de ISS. Na contramão dos demais municípios da sua região, Iomerê não possui cadastro de ISS.

Planta genérica de valores informatizada

Esta variável considera a existência no município de planta genérica de valores informatizada. A planta genérica de valores é um instrumento legal em que ficam determinados os valores unitários do metro quadrado de terreno e de construção do município, que possibilita calcular o valor de venda de cada imóvel no município. Na Região Oeste, 97 municípios $(82,20 \%)$ possuem planta genérica de valores informatizada, enquanto vinte municípios $(16,95 \%)$ possuem planta genérica de valores, porém não informatizada. Somente o município de Iomerê não possui planta genérica de valores. Ainda assim, a média da variável na região $(0,907)$ é superior àquela observada no estado $(0,899)$.

\section{Governo eletrônico}

O indicador governo eletrônico é medido por meio da variável serviços disponibilizados no portal do município. Trata-se do uso das tecnologias da informação e 


\section{Revista Cadernos de Economia}

Universidade Comunitária da Região de Chapecó - Unochapecó

comunicação para aprimorar a qualidade dos serviços e informações prestadas pelos municípios.

Serviços disponibilizados no portal do município

Esta variável considera o número de serviços disponibilizados no portal do município, do total de 12 elencados: consulta prévia para a obtenção de alvará provisório; diário oficial, legislação municipal e finanças públicas; concursos públicos; matrícula escolar na rede pública on-line; emissão de certidão negativa de débito e alvará; agendamento de consulta na rede pública de saúde; serviços informatizados do município e notícias; acesso a documentos e formulários; licitações; ouvidoria, serviço de atendimento ao cidadão; pregão eletrônico; e consulta a processos.

Nesta avaliação os municípios da Região Oeste, a exemplo dos municípios catarinenses $(0,480)$, não tiveram um bom desempenho $(0,483)$. Nenhum dos municípios atingiu o índice máximo (1,000). O município com melhor desempenho foi Chapecó $(0,833)$, ou seja, seu portal disponibiliza dez, dos doze serviços listados. Concórdia, Lindóia do Sul, Ouro, Palmitos, Videira, Xanxerê, Xaxim obtiveram índice de 0,750, disponibilizando nove desses serviços. Os municípios de Cunha Porã, Riqueza, São Carlos e São Domingos não disponibilizam serviços por meio de portal.

\section{Qualidade do quadro funcional}

Com relação à qualidade do quadro funcional, a variável analisada é o percentual de servidores com curso superior.

Percentual de servidores com curso superior (\%)

O nível de formação dos servidores públicos é o elemento mais importante para a qualificação da gestão de recursos. Em pesquisa nacional sobre a qualidade de gestão de pessoas nos municípios, o componente "nível de qualificação do quadro de pessoal" apareceu como a variável com maior força explicativa do Índice de Qualidade na Gestão de Pessoas (SECCHI, CARRER, BIROLO, 2012). Agentes públicos com formação superior em pedagogia, assistência social, enfermagem, medicina, administração, administração pública, 


\section{Revista Cadernos de Economia}

Universidade Comunitária da Região de Chapecó - Unochapecó

direito, contabilidade, entre outras, são capazes de colocar à disposição da Administração Pública conhecimentos e habilidades técnicas e gerenciais necessárias para a qualificação dos serviços. Soma-se a isto, a utilização de critérios de mérito (ex. nível de formação, experiência) que possam ser utilizados na gestão pública municipal para o preenchimento de cargos em comissão e assessoria, Embora, segundo pesquisa empreendida por Neuhaus, et al. (2016), estudos e relatos de casos sobre competências aplicadas a agentes públicos municipais em cargos de livre nomeação não foram localizados.

Dentre os municípios do Oeste catarinense, aqueles que possuem maior percentual de servidores com curso superior são Ipuaçu (47,14\%), Flor do Sertão $(70,80 \%)$ e Luzerna $(62,08 \%)$. O município com menor percentual foi Capinzal, com apenas 18,35\% de seus servidores com nível superior. O índice médio do Oeste catarinense foi de 0,755 , superior à média de Santa Catarina, que ficou em 0,740.

\section{Síntese dos indicadores de Gestão Pública}

A agregação dos indicadores referentes à Gestão Pública mostra um quadro favorável para os municípios do Oeste Catarinense. É o indicador com melhor avaliação dentro da dimensão “político-institucional”, com média 0,779 na escala de 0 a 1 . Comparativamente a Santa Catarina, o Oeste catarinense supera um pouco a média estadual, que ficou em 0,764. A região apresenta médias similares ao estado em todas as variáveis, com exceção da participação em consórcios públicos municipais, na qual se destaca 0,975 , frente a 0,894 estadual). No quadro 3, destacam-se os municípios do Oeste Catarinense com os melhores e piores índices em qualidade de gestão pública.

Quadro 3 - Melhores e piores índices em Gestão Pública municipal - Oeste Catarinense

\begin{tabular}{|c|c|}
\hline \multicolumn{1}{|c|}{ Município } & $\begin{array}{c}\text { Média do Índice de } \\
\text { Gestão Pública }\end{array}$ \\
\hline 1. Piratuba & 0,949 \\
\hline 2. Concórdia & 0,946 \\
\hline 3. Xanxerê & 0,940 \\
\hline$\ldots$ & \\
\hline 116. Coronel Martins & 0,593 \\
\hline 117. Faxinal dos Guedes & 0,563 \\
\hline 118. Xavantina & 0,525 \\
\hline
\end{tabular}

Fonte: SIDEMS (2018). 


\section{Revista Cadernos de Economia}

Universidade Comunitária da Região de Chapecó - Unochapecó

Além de aparecer em primeiro lugar no índice de qualidade de gestão pública, o município de Piratuba agregou o $3^{\circ}$ melhor índice em todo o estado, precedido por Joinville e Blumenau. No outro extremo, o município de Xavantina foi a pior administração pública municipal, neste quesito, em toda a região Oeste e a sétima pior no estado de Santa Catarina. O tamanho do município em termos populacionais parece ser uma variável explicativa forte com relação a variável, visto que dos 10 maiores municípios da região oito aparecem entre os 25 melhores, e apenas São Miguel do Oeste e Maravilha aparecem na 83a e $92^{a}$ posições, respectivamente.

Não surpreende que municípios maiores tenham à sua disposição pessoal com maior nível de formação técnica e gerencial, o que repercute na capacidade de elaboração de planos de cargos e salários e de capacitação que venham a atrair e manter servidores públicos mais qualificados que em municípios menores. Esta foi a conclusão dos estudos de Secchi, Carrer e Birolo (2013), mas pesquisas estatísticas de correlação são necessárias para corroboração desta hipótese no âmbito catarinense. O índice médio de Gestão Pública dos municípios do Oeste catarinense e os municípios com melhor e pior índice são destacados na Figura 2.

Figura 2 - Mapa do índice de Gestão Pública - Oeste Catarinense

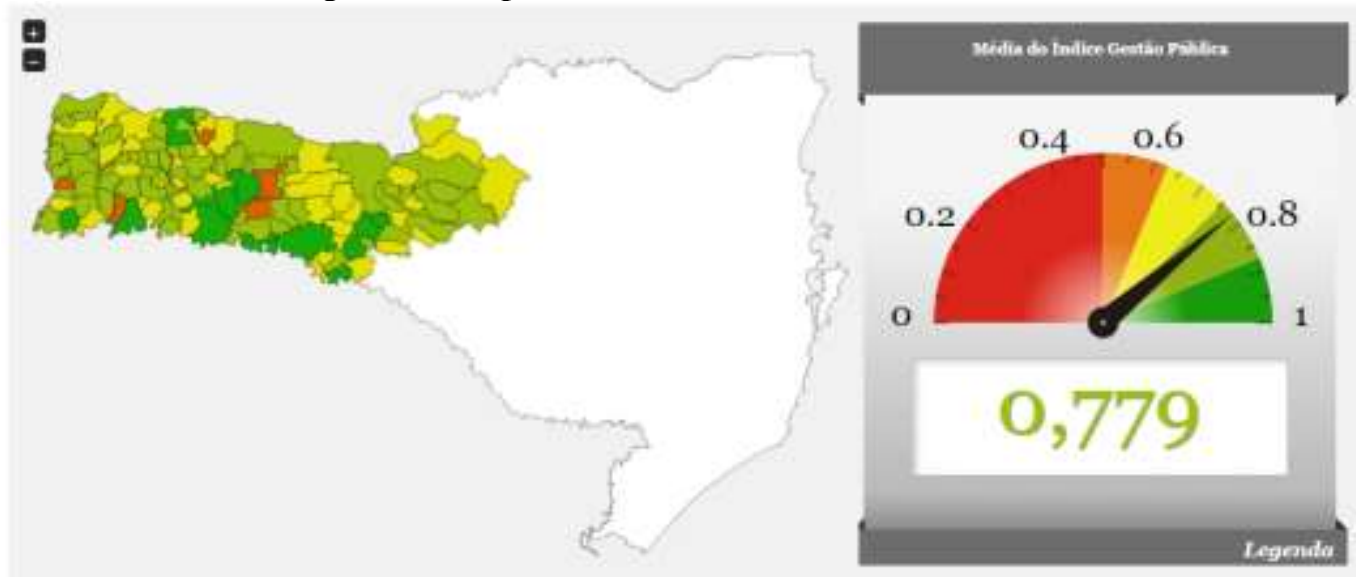

Fonte: SIDEMS (2018).

\section{INDICADORES DA PARTICIPAÇÃO SOCIAL}

Novos modelos de gestão pública têm mostrado que os avanços da administração devem ir muito além dos ferramentais técnicos para englobar elementos relacionais com a sociedade civil. O Novo Serviço Público (DENHARDT; DENHARDT, 2007) e as teorias da governança 


\section{Revista Cadernos de Economia}

Universidade Comunitária da Região de Chapecó - Unochapecó

pública (KOOIMAN, 2003) apontam para a participação social como elemento fundamental na elaboração, implementação e avaliação das políticas públicas. No sistema de indicadores da FECAM, os indicadores que operacionalizam a participação social são o percentual de participação eleitoral e o percentual de representatividade de gênero entre candidatos a vereadores.

\section{Participação eleitoral}

Com relação à participação eleitoral, a variável operacionalizadora é o percentual de comparecimento no pleito eleitoral de 2016.

Percentual de participação nos pleitos eleitorais (\%)

Os índices de abstenção eleitoral são um indicador importante da falta de interesse da população pela democracia e representação política. A variável participação nos pleitos eleitorais foi medida com base nas eleições municipais de 2016, tendo como fonte de dados o Tribunal Superior Eleitoral (TSE). Foi considerada baixa a participação os municípios que testemunharam a participação de 78,21\% a 89,10\% dos eleitores, enquanto os municípios com valores mais altos foram aqueles que tiveram participação superior a 97,28\%. Os dois municípios com maior afluência às urnas em 2012 foram Presidente Castello Branco (98,45\% de comparecimento, índice 0,929) e Marema (96,87\% de comparecimento, índice de 0,856), enquanto o pior foi Abelardo Luz (80,74\% de afluência às urnas, e índice 0,116). Interessante notar que entre os dez piores classificados nesta variável incluem-se municípios-polo, como São Miguel do Oeste, Fraiburgo, Caçador, Videira, Xanxerê e Joaçaba. Concórdia $\left(106^{\circ}\right)$ e Chapecó $\left(107^{\circ}\right)$ também aparecem entre os últimos nos indicadores de participação em pleito eleitoral, o que remete à hipótese que quanto maior o número de eleitores, menor o engajamento de sua população na participação eleitoral. A média regional ficou em 90,45\% de comparecimento, superior à média estadual que ficou em $89,56 \%$.

\section{Representatividade de gêneros}




\section{Revista Cadernos de Economia}

Universidade Comunitária da Região de Chapecó - Unochapecó

Com relação à representatividade de gêneros, a variável operacionalizadora foi a equidade de gêneros entre os candidatos a vereadores no município.

Representatividade de gêneros entre candidatos a vereadores (\%)

Desde 1934, com a permissão do voto feminino no governo de Getúlio Vargas, a participação feminina na política é tema recorrente na discussão sobre o aprofundamento democrático brasileiro. Ainda hoje a participação de mulheres em partidos políticos, mulheres candidatas e mulheres eleitas aos cargos de representação política têm sido baixas, colocando o Brasil na $132^{a}$ posição em número de mulheres no parlamento (IPU, 2019), com mulheres ocupando apenas 15\% das vagas na Câmara dos Deputados e 14,8\% no Senado.

A FECAM avalia a representatividade de gênero por meio da razão entre o número de candidatas mulheres sobre o total de candidatos a vereadores nos municípios. Na região Oeste catarinense a média registrada foi de $33,57 \%$, sendo que os municípios que se destacaram foram Alto Bela Vista (42,31\%), São Miguel da Boa Vista (39,29\%) e Paial (39,29\%). A lei eleitoral brasileira determina a presença mínima de 30\% de mulheres na formação de chapas para os cargos legislativos e a Justiça Eleitoral determinou em 2018 que partidos também destinem 30\% do Fundo Especial de Financiamento de Campanhas para as candidaturas femininas. Não alcançaram esses índices os municípios de Águas de Chapecó $(29,17 \%)$ e Ipira $(29,63 \%)$. Comparativamente à média dos índices municipais estaduais $(0,583)$, os municípios do Oeste tiveram desenvolvimento similar na representatividade de gêneros entre candidatos a ao poder legislativo (índice regional 0,589).

\section{Síntese dos indicadores de participação social}

A agregação dos indicadores de participação social também revela que a região Oeste está à frente da média catarinense, com índice médio de 0,575, contra 0,552 de todos os municípios de Santa Catarinense. No quadro 4 estão destacados os municípios campeões e os piores colocados nos índices de participação social no Oeste catarinense. 


\section{Revista Cadernos de Economia}

Universidade Comunitária da Região de Chapecó - Unochapecó

Quadro 4 - Melhores e piores índices em Participação Social municipal/Oeste Catarinense

\begin{tabular}{|r|c|}
\hline \multicolumn{1}{|c|}{ Município } & Média do Índice de Gestão Pública \\
\hline 1. Alto Bela Vista & 0,760 \\
\hline 2. São Miguel da Boa Vista & 0,744 \\
\hline 3. Cunhataí & 0,735 \\
\hline ... & \\
\hline 116. Fraiburgo & 0,359 \\
\hline 117. Abelardo Luz & 0,324 \\
\hline 118. São Miguel do Oeste & 0,310 \\
\hline
\end{tabular}

Fonte: SIDEMS (2018).

Além de aparecer no topo do ranking na região Oeste catarinense, os municípios de Alto Bela Vista, São Miguel da Boa Vista e Cunhataí figuram na $1^{\mathrm{a}}, 4^{\mathrm{a}}$ e $6^{\mathrm{a}}$ colocações entre todos os municípios catarinenses. São Miguel do Oeste é o quarto município de toda Santa Catarina com pior índice de participação social. Na figura 3, destaca-se estes extremos e a média regional.

Figura 3 - Mapa do índice de Participação Social - Oeste Catarinense

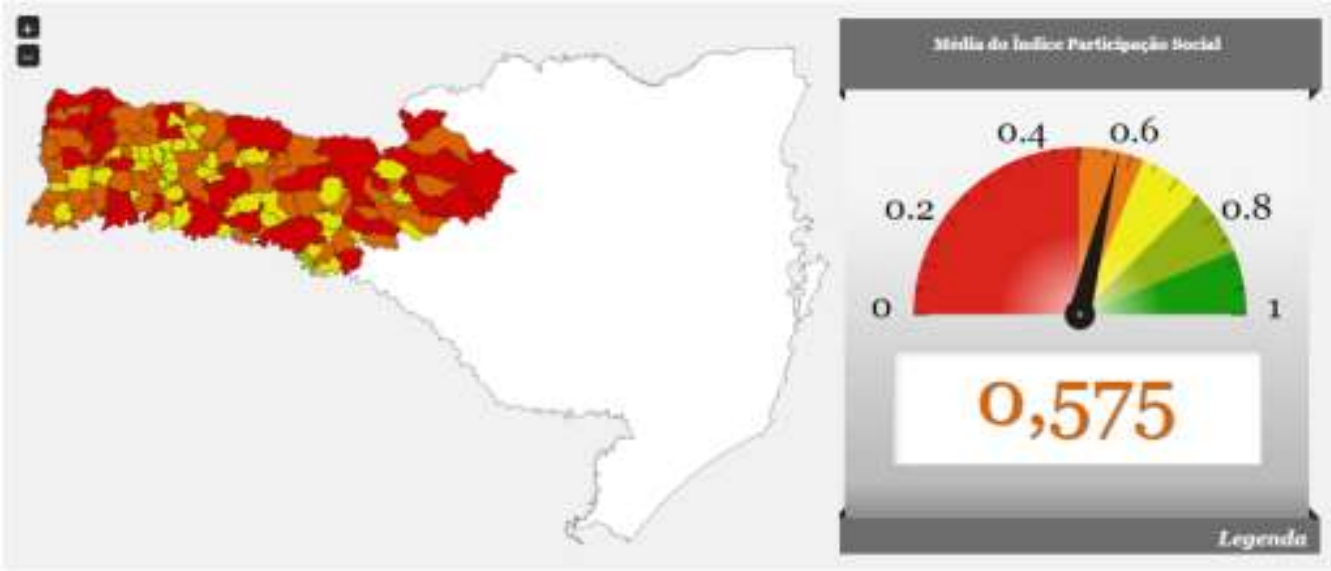

Fonte: SIDEMS (2018).

\section{AGREGAÇÃO DOS INDICADORES: A DIMENSÃO POLÍTICO-INSTITUCIONAL}

Após realizar análise individualizada de todos os indicadores, cabe realizar uma síntese da dimensão político-institucional dos municípios do Oeste catarinense. Esta síntese é feita por meio das médias dos indicadores agregados nas categorias Finanças Públicas, Gestão Pública e Participação Social. A média de todos os municípios na dimensão políticoinstitucional ficou em 0,674 , superior à média do estado de Santa Catarina $(0,652)$. Na agregação dos índices da dimensão político-institucional o Oeste aparece na primeira 


\section{Revista Cadernos de Economia}

Universidade Comunitária da Região de Chapecó - Unochapecó

colocação $(0,674)$, seguido do Vale do Itajaí $(0,659)$, Sul Catarinense $(0,638)$, Norte Catarinense $(0,614)$ e Grande Florianópolis $(0,606)$. A região Serrana aparece na última colocação com média dos indicadores municipais igual a 0,577.

É importante destacar que em todos os indicadores estudados, a média dos indicadores dos municípios do Oeste praticamente igualou ou superou a média catarinense, com exceção de três variáveis: percentual de receita própria sobre a receita corrente líquida, cadastro de ISS informatizado e planos de desenvolvimento setoriais. No quadro 5 estão destacados em cor verde as variáveis em que o Oeste catarinense apareceu com médias acima da média catarinense, em cor vermelha as três variáveis em que as médias foram comparativamente inferiores para o Oeste catarinense, em amarelo as variáveis que ficaram praticamente empatadas com a média catarinense. Pode-se afirmar, portanto, que considerados as variáveis estudadas nos indicadores da FECAM, os municípios do Oeste estão mais bem estruturados na dimensão político-institucional, tanto em finanças públicas, qualidade da gestão pública e participação social do que a média dos municípios de Santa Catarina. 


\section{Revista Cadernos de Economia}

Universidade Comunitária da Região de Chapecó - Unochapecó

Quadro 5 - Síntese das comparações entre municípios do Oeste com Santa Catarina

\begin{tabular}{|l|c|c|}
\hline \multicolumn{1}{|c|}{ Variável } & Oeste & Santa Catarina \\
\hline Receita Corrente Líquida Per Capita & $\mathrm{R} \$ 4.498,96$ & $\mathrm{R} \$ 3.769,76$ \\
\hline $\begin{array}{l}\text { Percentual de receita própria sobre a } \\
\text { Receita Corrente Líquida }\end{array}$ & $7,24 \%$ & $9,78 \%$ \\
\hline Investimento público per capita & $\mathrm{R} \$ 500,22$ & $\mathrm{R} \$ 415,58$ \\
\hline $\begin{array}{l}\text { Percentual de investimento público sobre a } \\
\text { Receita Corrente Líquida }\end{array}$ & $11,11 \%$ & $0,85 \%$ \\
\hline $\begin{array}{l}\text { Percentual de Endividamento Público } \\
\text { Municipal }\end{array}$ & 0,988 & 0,988 \\
\hline Suficiência de Caixa & 0,992 & $50,28 \%$ \\
\hline $\begin{array}{l}\text { Percentual da Receita comprometida com } \\
\text { Folha de Pessoal }\end{array}$ & $47,66 \%$ & 0,894 \\
\hline $\begin{array}{l}\text { Participação em Consórcios } \\
\text { Intermunicipais }\end{array}$ & 0,966 & 0,757 \\
\hline Planos de Desenvolvimento Setoriais & 0,730 & 0,740 \\
\hline $\begin{array}{l}\text { Percentual de Servidores com Curso } \\
\text { Superior }\end{array}$ & 0,755 & 0,988 \\
\hline Cadastro Imobiliário Informatizado & 0,987 & 0,969 \\
\hline Cadastro de ISS Informatizado & 0,958 & 0,899 \\
\hline Planta Genérica de Valores Informatizada & 0,907 & 0,480 \\
\hline $\begin{array}{l}\text { Serviços Disponibilizados no Portal do } \\
\text { Município }\end{array}$ & 0,483 & $89,56 \%$ \\
\hline $\begin{array}{l}\text { Percentual de Participação nos Pleitos } \\
\text { Eleitorais }\end{array}$ & $90,45 \%$ & 0,583 \\
\hline $\begin{array}{l}\text { Percentual de Representatividade de } \\
\text { Gêneros entre Candidatos a Vereadores }\end{array}$ & 0,589 & \\
\hline
\end{tabular}

Fonte: elaboração própria com base em SIDEMS (2018).

Há que fazer algumas ponderações. A primeira delas é que estes indicadores são arbitrários. O sistema de indicadores da FECAM tem uma metodologia própria, com indicadores criados por uma equipe técnico-cientifica que seguiu determinada metodologia, critérios e fontes específicas. Se o número de indicadores fosse ampliado ou reduzido, ou a fonte de dados fosse diferente ou mesmo os pesos para cada variável fosse diversa ter-se-ia, necessariamente, resultados diferentes.

Também é necessário frisar que as dimensões não são comparáveis umas com as outras. Dizer que a média dos indicadores de Finanças Públicas foi 0,671, qualidade na gestão pública 0,779 e participação social 0,575 não quer dizer que a qualidade na gestão pública está melhor que as finanças públicas ou que a participação social é onde há mais espaço para melhorias. As variáveis e indicadores da FECAM são mais úteis para fazer comparações entre municípios, entre regiões e tirar médias estaduais, do que para comparar "maçãs" e "peras". 


\section{Revista Cadernos de Economia}

Universidade Comunitária da Região de Chapecó - Unochapecó

Com relação tamanho do município e a qualidade dos indicadores, percebe-se que municípios mais populosos e menos populosos se alternam na distribuição no ranking. Entre os 118 municípios do Oeste catarinense, destaca-se os três melhores municípios, os três piores, e os 10 maiores municípios em população, no quadro 6.

Quadro 6 - Melhores e piores índices na dimensão Político Institucional - Oeste Catarinense
\begin{tabular}{|l|c|}
\hline \multicolumn{1}{|c|}{ Município } & Índice na dimensão político-institucional \\
\hline 1. Bom Jesus do Oeste & 0,833 \\
\hline 2. Piratuba & 0,801 \\
\hline 3. Princesa & 0,800 \\
\hline 4. Joaçaba & 0,799 \\
\hline 7. Videira & 0,774 \\
\hline 26. Fraiburgo & 0,731 \\
\hline 37. Chapecó & 0,716 \\
\hline 41. Concórdia & 0,711 \\
\hline 56. Caçador & 0,680 \\
\hline 59. Maravilha & 0,676 \\
\hline 83. Xanxerê & 0,623 \\
\hline 89. São Miguel do Oeste & 0,613 \\
\hline 96. Xaxim & 0,601 \\
\hline 116. Belmonte & 0,535 \\
\hline 117. Irani & 0,535 \\
\hline 118. Lebon Régis & 0,510 \\
\hline
\end{tabular}

Fonte: SIDEMS (2018).

Observam-se os dois extremos: de um lado temos o município mais bem classificado, Bom Jesus do Oeste, um pequeno município que conta com 2.132 habitantes (IBGE 2015), sem acesso asfáltico, emancipado apenas em 1995 do município de Modelo. Com todas as dificuldades de arrecadação, de atração e retenção de bons recursos humanos, Bom Jesus do Oeste ficou na 3 a colocação no estado e em primeiro lugar no Oeste, à frente de municípiospolo como Joaçaba, Chapecó e Concórdia. No outro extremo aparece Lebon Régis, também pequeno, mas com uma população já na casa dos 11.862 (IBGE, 2000), com acesso asfáltico, emancipado desde 1958 do município de Curitibanos. 


\section{Revista Cadernos de Economia}

Universidade Comunitária da Região de Chapecó - Unochapecó

Figura 4 - Mapa da dimensão político institucional - Oeste catarinense

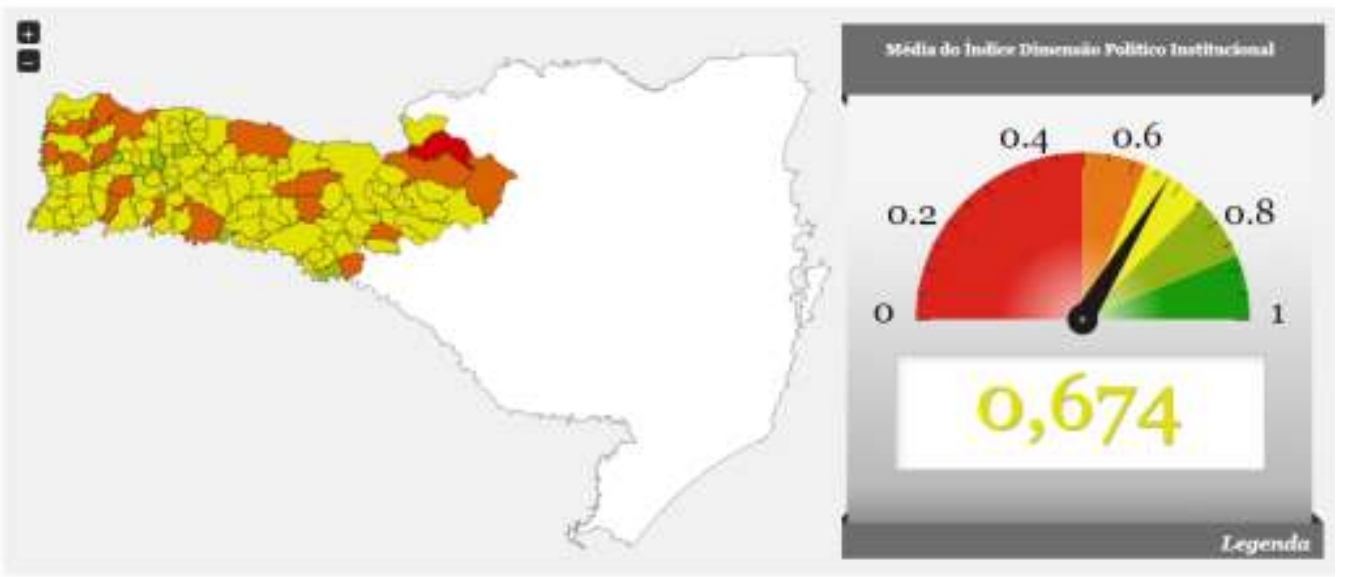

Fonte: SIDEMS (2018).

Pesquisas qualitativas de caráter explicativo são necessárias para destrinchar esses resultados contra-intuitivos e justificar por que um município consegue bons resultados apesar das condições socioeconômicas desfavoráveis para a gestão pública. Indica-se aprofundamento de questões que permeiem temas como a liderança política, a cultura cívica e senso comunitário, algum evento extraordinário ou mesmo falhas metodológicas ou de fontes para os indicadores.

\section{CONSIDERAÇÕES FINAIS}

A partir da análise da dimensão político-institucional dos municípios do Oeste catarinense, realizada por meio do cotejamento das médias dos indicadores agregados nas categorias Finanças Públicas, Gestão Pública e Participação Social, foi possível constatar que os municípios da região Oeste de Santa Catarina apresentam, nesta dimensão, índices superiores à média do estado. São inferiores à média municipal de Santa Catarina, apenas no que se refere ao percentual de receita própria sobre a receita corrente líquida, elaboração de planos de desenvolvimento setoriais e cadastro informatizado de ISS. Considera-se que embora os resultados estejam favoráveis se tomados estes indicadores, o desenvolvimento sustentável de uma região, além de um contínuo vir a ser, ainda requer apreciações qualitativas capazes de captar um conjunto considerável de dimensões, bem como a sua consistente articulação e distribuição pelo tecido social e pelo território. 


\section{Revista Cadernos de Economia}

Universidade Comunitária da Região de Chapecó - Unochapecó

Assim, além da necessidade de melhoria contínua, calibragem e refinamento no Sistema de Indicadores utilizado para este estudo (SIDEMS), aponta-se que a qualidade da gestão pública capaz de gerar desenvolvimento regional, contempla a superação de desigualdades intra e inter-regionais, demonstradas pelos dados apresentados, quando se observou que municípios do mesmo porte e por vezes vizinhos, apresentam resultados díspares. Dadas às relações de interdependência, mesmo que um município desponte em um ou outro indicador, se observada a região Oeste, é possível perceber lacunas na gestão pública municipal no que se refere à dimensão político-institucional, que podem acarretar efeitos de perda da qualidade da gestão pública deste território.

Como apontado por Frare et. al. (2020), a utilidade dos sistemas de indicadores também deve perpassar a sua capacidade de gerar informações úteis para a melhoria da prática gerencial. Neste sentido, reveste-se de importância o aprimoramento e o uso de indicadores para o apoio à decisão de gestores públicos municipais. Também relevante é o seu uso combinado com outras fontes de dados, incluindo aqueles de natureza qualitativa, formando base de conhecimento capaz de fornecer caminhos para formulação, gestão, implementação e avaliação de políticas públicas necessárias ao desenvolvimento local e regional.

O associativismo, fundamentado no senso comunitário, estão presentes na cultura catarinense e suas marcas se fazem notar na região Oeste produzindo, possivelmente, os resultados positivos na dimensão político-institucional, quando a região é comparada com o estado de Santa Catarina (MARQUES, DIAS, 2003; SCHERER-WARREN, CHAVES, 2004). Mas aponta-se a necessidade de estudos futuros, sobretudo de natureza qualitativa, que possam observar, para além do dado positivado, as formas cotidianas de governança e gestão destes municípios em sua particularidade, bem como em sua interação regional. Os resultados deste estudo sugerem ainda nova investigação capturando a percepção de lideranças e de cidadãos, sujeitos do desenvolvimento regional, acerca do estilo de desenvolvimento que anseiam para a região, a fim de melhor avaliar se os resultados mensurados pelos indicadores político-institucionais estão alinhados a estas demandas coletivas. 


\section{Revista Cadernos de Economia}

Universidade Comunitária da Região de Chapecó - Unochapecó

\section{REFERÊNCIAS}

Abrucio, F. L.; Filippim, E. S.; Dieguez, R. C. Inovação na Cooperação intermunicipal no Brasil: a experiência da Federação Catarinense de Municípios na construção de consórcios públicos. Revista de Administração Pública (Impresso), v. 47, 2013 p. 1543-1592.

Arretche, M. Democracia, federalismo e centralização no Brasil. Rio de Janeiro Fiocruz, 2012.

Bergue, S. T. Gestão de Pessoas em Organizações Públicas. 3. ed. Caxias do Sul: EDUCS, v. 1,2010 .

Castor, B. V. J. O Brasil não é para amadores: Estado, governo e burocracia na terra do jeitinho. 2. ed. Curitiba: Travessa Editores, 2004.

Clementino, M. L. M. Finanças públicas no nível local de governo. Cadernos Metrópole, n. 4, 2000, pp. 159-182.

Denhardt, J. V.; Denhardt, R. B. (2007). The New Public Service: Serving, not steering. Expanded Ed. New York: Armonk.

Fecam. Guia dos municípios catarinenses. 2020. Disponível em: https://guia.fecam.org.br/filtro?categorias\%5BAssocia\%C3\%A7\%C3\%B5es+de+Munic\%C3 \%ADpios+-+SC\%5D=1, Acesso em 20 de fevereiro de 2020.

Frare, M.B. Gestão de indicadores de sustentabilidade nos pequenos municípios do Oeste catarinense. [Dissertação de Mestrado] Mestrado Profissional em Administração. Chapecó: Universidade do Oeste de Santa Catarina, 2019.

Frare M. B., Clauberg A. P. C., Sehnem S., Campos L. M. S., Spuldaro J. Toward a sustainable development indicators system for small municipalities. Sustainable Development. Vol. 28, 2020, pp. 1148-1167.

IPU. Women in National Parliaments. 2019. Disponível em: http://archive.ipu.org/wmne/classif.htm, acesso em 20 de fevereiro de 2020.

Kooiman, J. Governing as governance. London: SAGE, 2003.

Marques, V. M., Dias, L. C. Associações de municípios em Santa Catarina: da gênese à consolidação. Geosul, v. 18, n. 36, 2003, pp. 29-53.

Neuhaus, L.; Moreschi, R. K.; Avila, M.C.; Filippim, E. S. Mapeamento de Competências para Cargos Municipais Comissionados. In: Encontro Bienal de Alunos de Pós-Graduação 


\section{Revista Cadernos de Economia}

Universidade Comunitária da Região de Chapecó - Unochapecó

em Administração - EBAA, 2016, Rio de Janeiro/RJ. Anais (online). Rio de Janeiro: EBAA, 2016.

Putnam, R. D. Comunidade e democracia: a experiência da Itália moderna. Rio de Janeiro: Editora Fundação Getúlio Vargas., 1996.

Réus, I. Gestão municipal e desenvolvimento sustentável: um estudo dos indicadores de sustentabilidade nos municípios catarinenses. Dissertação de Mestrado. Programa de PósGraduação em Administração (PPGA/ESAG/UDESC). Florianópolis, UDESC, 2012. Réus, I.; Secchi, L. ; Filippim, E. S.; Rossetto, A. M. (2010). A gestão de pessoas nas prefeituras municipais catarinenses: um ativo estratégico para o desenvolvimento. In: Encontro Nacional de Administração Pública e Governança - EnAPG, 2010, Vitória. Anais do EnAPG, 2010.

Santos, C. S. Introdução à gestão pública. 2. Ed. São Paulo: Saraiva, 2014.

Scherer-Warren, I., CHAVES, I. Associativismo civil em Santa Catarina. Trajetórias e tendências. Florianópolis: Insular, 2004.

Senado. Municípios podem ter maior fatia de tributos arrecadados pela União. 2014. Agência Senado [On-line] Disponível em: http://www12.senado.leg.br/noticias/materias/2014/05/19/ municipios-podem-ter-maior-fatia-de-tributos-arrecadados-pela-uniao, Acesso em 01/03/2016.

Sidems. Sistema de Indicadores de Desenvolvimento Municipal Sustentável. 2018. Disponível em: http://indicadores.fecam.org.br/ Acesso em: 20 de fevereiro de 2020.

Siebert, Claudia. Arranjos institucionais e trajetória do planejamento territorial em Santa Catarina, Revista Paranaense de Desenvolvimento, n. 119, jul./dez., 2010, pp. 137-167. Tatagiba, L. Conselhos gestores de políticas públicas e democracia participativa: aprofundando o debate. Revista Sociologia Política, v. 25, 2005, pp. 209-213. 